\title{
The Impact of Investor Sentiment on Returin of Different Industries in Pakistan
}

\begin{abstract}
Abdul Rashid ${ }^{1}$, Sumayya Chughtai' ${ }^{2}$, Madiha Fayyaz ${ }^{3}$
${ }^{1}$ International Institute of Islamic Economics (IIIE), IIU Islamabad Pakistan

${ }^{2}$ Deptt: of Accounting \& Finance, Faculty of Management Sciences, IIU Islamabad Pakistan

3International Institute of Islamic Economics (IIIE) IIU, Islamabad, Pakistan

\section{A B S T R A C T}

We classify stocks in different industries to measure industrial sentiment based on principle component analysis in order to examine whether investor sentiment exerts a differential impact on stock returns across different industries. After having constructed industry-level sentiment indices we construct a composite investor sentiment index. Our results suggest that investor sentiment negatively affects current as well as future stock returns in Pakistan over the examined period. However, we find that the influence of investor sentiment varies substantially across different industries. We also find that the market sentiment index has a negative relationship with both current and future stock returns. We also show that the direction of the relationship between return and sentiment remains same for the current and future period. This indicates that investors overreact to the available information and mispricing exists for a prolonged time. Our results confirm that sentiment driven mispricing persists for upcoming time and stock markets are not fully efficient to adjust instantaneously.
\end{abstract}

JEL Classification: B26, G02, G12, and G13

KEYWORDS: Stock Returns; Industrial Sentiment; Behavioural Biases; Return predictability; Composite Index

\section{INTRODUCTION}

Standard finance theory claims that the determination of asset prices is an unbiased process and it is mainly based on the maximization of expected utility. However, it has been argued that standard finance theory is unable to explain stylized patterns of stock returns due to the existence of a huge gap in theory and practice. Principally, standard finance theories are based on several unrealistic assumptions. These assumptions include:

\begin{tabular}{lc}
\hline Address of Correspondence & Article info \\
Sumayya Chughtai & Received July 11, 2017 \\
Sumayya.chughtai@iiu.edu.pk & Accepted Dec 22, 2017 \\
& Published Dec 30, 2017
\end{tabular}


financial markets are efficient, investors are rational, asset prices are determined by the CAPM, and investors maximize their expected utility based on the mean-variance approach.

However, significant historical events put several questions on the validity of these assumptions. A major shortcoming of standard finance models is the assumption of rational and unemotional investors. In fact, investors are distracted due to their judgmental and emotional biases. Several historical financial markets' crashes and bubbles were difficult to explain by the advocates of standard finance in the framework of conventional finance theories. For example, black Monday in 1987, tech bubble crash in 2000, and real estate bubble crash in 2008 highlight the consequences of the effect of behavioural biases or investor sentiment on stock prices ${ }^{1}$. In these uncertain events, stock prices significantly deviate from fundamental value of stocks. However, classical asset pricing models have largely been failed to explain or predict these price deviations.

One of the possible reasons for price deviation from the fundamental value, particularly in shock periods, is irrational trading, which drives the stock price up and up. However, arbitrage activity failed to bring prices back to their intrinsic value. Hence, we can say that the main reasons for the stock market crash are investor's irrational decision making rather than the changes in the fundamental value of firms (Shiller, 1987).

Market efficiency implies that market forces (demand and supply) can fairly determine stock price and return predictability is not possible using any sort of information (Fama, 1965). Nonetheless, empirical evidence indicates that although it is hard to beat the market every time, returns can be predicted. Further, some studies have documented that stock returns can be predicted by using the information on humans' sentiment. ${ }^{2}$ Irrational investment decisions by economic agents drive away the market from settling at the equilibrium. Excess volatility, which indicates the existence of high investor sentiment in the stock market, can cause deviation of market prices from intrinsic value, which provides

\footnotetext{
${ }^{1}$ Baker and Wurgler (2007) defined investment sentiment as, "Belief about future cash flows and investment risks which is not defined by the facts at hand".

${ }^{2}$ See Cohen and Frazzini (2008), Glushkov and Bardos (2012), and Lutz (2015). Schmeling (2009) estimate the future returns, which are depending upon the sentiment, i.e. $r_{t+1}=\alpha+\beta$ Sentiment $_{t}+\eta_{t}$.
} 
evidence that the markets are not efficient. It is expected that investor sentiment has a strong, significant impact on asset prices and can result in substantial deviation of stock prices from the intrinsic value. Another possible channel is that investor sentiment affects trading activity, which, in turn, influences stock prices (Wu, Liu, \& Chen, 2016). Further, some scholars argue that investor sentiment significantly affects investment and financing decisions of individuals, affecting their buying, selling, and holding decisions, which ultimately affects stock prices (McLean \& Zhao, 2014).

This is the first extensive study of Pakistan that measures and analyses the impact of investor sentiment on industrial returns and stock market performance. It is worthwhile to analyse the pattern of sentimental waves in Pakistan because biased decision-making is prominent here due to the majority of individual investors in Pakistan. ${ }^{3}$ We measure industry-level and overall national level sentiment and its influence on respective stock returns. We use financial market proxies, namely equity share, volatility premium, and turnover, to measure investor sentiment. By utilizing these proxies, we construct investor sentiment index based on the principal component analysis (PCA) for each industry included in the sample. After having constructed the industry-level investor sentiment index, we construct a composite investor sentiment index. Finally, we examine the effect of investor sentiment on contemporaneous and future stock returns using firm-level data in a pooled regression framework. We also examine investor sentiment effects differ across different industries. In general, our results suggest that investor sentiment has a significant effect on stock returns both at market and industry level. Specifically, we find that market level stock returns are negatively and significantly affected by investor sentiment. Based on the industry specific analysis, we show that the direction of investor sentiment on stock returns substantially varies across different industries. For most of the examined industries, sentiment has a tendency to significantly affect the current and future stock returns.

The rest of this paper is divided into following sections. Section 2 reviews the literature. Section 3 describes the issues related to data and methodology. Section 4 presents the results of the empirical analysis. Section 5 concludes the paper.

\footnotetext{
${ }^{3}$ Finter and Ruenzi (2012) assert that individual investors are more sensitive to sentiment fluctuations.
} 


\section{LITERATURE REVIEW}

There is a quote by Albert Einstein, "two things are infinite. The universe and human stupidity... and I am not so sure about the universe." Along with limited rationality, humans have a tendency to be overconfident. Cognitive biases create anomalies and people believe they are making right decisions. Individuals make illogical decisions by following social contagion. Classical finance holds that rational investors play the main role and their investment strategies determine asset prices. These are representative agents and are not prejudiced by human error, and hence, they make unbiased forecasts most of the time. However, Thaler (1999) criticizes this viewpoint due to the involvement of hypothetical assumptions.

In order to make rational investment decisions, the following conditions must hold: the majority of rational investors, costless short selling, and quasi-rational investor cannot short sell. All of these aforementioned assumptions are difficult to fulfil in reality and make difficult practical implications of efficient market hypothesis. Baker \& Wurgler (2007) are of the view that rational investors cannot eliminate the role of noise trader but only can mitigate the role of noise traders. In standard finance, efficiency in the capital market is only limited to correction of asset prices. It does not take into account the administration and organization of capital markets. Two fundamental aspects are speed and quality of adjustment. According to the efficient market doctrine, managers should passively manage portfolios, as the market is active enough to rectify overpricing and under-pricing. And, in the scenario of perfect markets, active portfolio management would be just wastage of resources.

The efficient market hypothesis (EMH) further claims that stock prices follow a random walk and their behaviour is unpredictable. Random walk implies no autocorrelation between returns. However, Bondt and Thaler (1985) ascertain that stocks follow the underlying distribution, which assists in predicting returns and helps in earning abnormal returns - returns excess of required level. On another side, efficiency in 
conventional finance implies that security prices reflect all relevant information, so no more room for return predictability based on any past, publically available and even private information.

Behavioural finance is not a total replacement for conventional finance. Rather, it can be considered augmentation of standard finance theories and models. Specifically, it relates to human psychology and its mechanism to the financial decision-making process. Markets are not always efficient. This inefficiency exists due to unexplained variations in stock markets. These markets anomalies need to explain by relaxing the rigorous assumptions of standard finance. Market anomalies linked with cognitive errors, which can heavily stimulate portfolio management and asset trading decisions.

According to standard finance, investors make investment decisions according to the mean-variance criterion. Only the risk factor is enough to explain all type of fluctuations in stock returns. Market efficiency also assumes information mechanism is perfect and all economic agents have access to accurate information. Investors are assumed rational enough to exploit perfect information to gain abnormal profit. However, Burghardt (2011) states that behaviour of investors is correlated with each other and they generally trade in-group. Correlated beliefs of investors are a barrier to automatic market adjustment mechanism. Furthermore, according to the conventional school of thought, perfect arbitrage is possible. Fully rational arbitrageurs enjoy excess profit and equate the market value of assets to fundamental values. Fama (1965) determines that arbitrage activity keep the capital market at an equilibrium level and hence stock markets are efficient.

Behavioural finance can reconcile market inefficiency by incorporating the effect of loss aversion, overconfidence, overreaction, and mental accounting. Burghardt (2011) is of the view that behavioural finance is based upon a positive theory in which we study how individuals actually behave rather than how they should behave. Statman (2014) clearly indicates that behavioural finance is subject to the concept of normal investors. Normal investors do not follow the exact rule of profit maximization. ${ }^{4}$ They are far away from the pattern of rational trading. The existence of biases and emotions can affect

\footnotetext{
${ }^{4}$ Statman (2010) defined behavioral finance as "an attempt to understand investors and reflection of their interactions in financial markets".
} 
investors' investment decisions. Biases arise from expectations, experiences, and faulty framing, which can affect investors' emotions. ${ }^{5}$ These emotional biases make ways for irrational and sentimental trading. Thus, behaviour finance serves as a bridge between theory and practice.

Empirical evidence shows that stock markets are inefficient and stock prices regularly deviate from fundamental values. Berger and Turtle (2012) suggest that capitalization on mispricing is not always possible due to lack of information availability and accuracy. Arbitrageurs are limited in their ability to get full market information, to process available information, and to bring prices back at parity (Baker \& Wurgler, 2007).

Advocates of standard finance consider mispricing is a short-term phenomenon and rational arbitrageurs will keep the market at justifiable level. However, arbitrage remains incomplete due to unpredictable movement in prices. The existence of few rational investors could not reverse the effect of irrational investors and arbitrage would remain incomplete.

Arbitrage activity is based on the availability of perfect substitutes and price differential. Although, in the real world, most stocks do not have perfect substitutes and markets do not instantaneously come up to the equilibrium level. Standard finance considers arbitrage as a riskless activity. But, in behavioural context, it is considered as risky activity. Arbitrageurs have short time span and they have to liquidate their positions before the settlement market.

The existence of psychological impact in investment decisions is a fatal problem for practical implications of efficient market hypothesis as it depends totally on rationality. Investor sentiment can cloud capacity of rational judgment. Incorporation of behavioural factors can enhance understanding of financial markets. Biological systems have scarce resources and the human brain can make satisfying decisions rather than perfectly rational decisions (Sapra \& Zak, 2010). The existence of individual investors makes the impact of sentiment positive and forms bases for return predictability(Finter \& Ruenzi, 2012). Gupta and Basu (2011) claim that stock markets in emerging economy are not efficient.

${ }^{5}$ Faulty framing is a trend in which investors only consider purchase price and does not mark value of stock according to market. 
Investor sentiment relates to spurious beliefs. Investors are prone to subjective biases about fundamental value, so we cannot expect stock markets to be objectively correct. The influence of sentiment on stock returns varies with experience of emotion and good and bad memories. Practically, investment decision-making does not only base on facts and obvious information but also on many psychological aspects (Shefrin, 2014).

Empirical evidence also shows that a strong negative relationship exists between current sentiment and subsequent returns for speculative stocks (Lutz, 2010). According to the existent literature, investors' thoughts and beliefs vary across regions, countries, and institutions. Investor sentiment has a diverse effect on stock return and this diversity varies with the type of securities. Some securities are less traded on the stock exchange, as they are considered difficult to arbitrage (Baker \& Wurgler, 2006). Sentiment-risk will vary in the same direction if the same fundamental risk is associated with the stock (Shleifer, 2000). Hence, firms in one industry doing the same type of business activity will share common sentiment exposure. However, it is very likely that the impact of sentimental waves varies across industries. It has a significant influence on less stable industries and an insignificant on others (M.-P. Chen, Chen, \& Lee, 2013).

Baker and Wurgler (2006) state that valuation of young firms is a more biased process and heavily depends on sentiment. Based on this finding we can infer the same for undeveloped industries. Risk level and return margin differ across industries and industry factor can affect investment performance. Limited experience and rumours in the stock market can provoke sentimental biases. It may stimulate investors to trade without any reason and misestimate stock performance.

\section{RESEARCH METHODOLOGY}

To achieve the objective of investor sentiment measurement, we construct our industry level investor sentiment indices by using three financial indicators, namely, volatility premium, equity share, and turnover. For this purpose, we use annual data for all non-financial firms listed at Pakistan Stock Exchange (hereafter PSX). Our data sample covers the time of fourteen years spanning from 2000 to 2013. To achieve the objective of 
investor sentiment measurement, we collect data on share prices and turnover from the official website of PSX. ${ }^{6}$ We obtain the data on shareholder's equity, preferred equity, long-term debt, and the number of shares outstanding from the publication of State Bank of Pakistan, 'Financial Statement Analysis of Companies (Non-Financial) listed at PSX'. We classify our sample firms into different thirteen industries by following the structure of classification used by State Bank of Pakistan. These industries are Sugar, Textile Composite, Engineering, Health Care, Construction, Consumer Products, Automobile, Fuel \& Gas, Stationary, Energy, Chemicals, Technology, and Miscellaneous.

Table 1 presents the organization of the industries. We classify industries into a wider set of firms to lessen a total number of industries, and end-up with thirteen industries. In miscellaneous industries, we group the firms that deal with luxurious products. These industries have a very few number of firms registered at PSX.

Table 1: Industrial Classification

\begin{tabular}{lll}
\hline \hline $\mathrm{N}$ & Industry & Subgroup of Industries \\
\hline \hline 1 & Sugar & Sugar and Allied Industries \\
2 & Textile & Spinning, Weaving, sports dresses, kids \\
3 & Engineering & Electrical machinery and air products \\
4 & Health Care & Pharmaceuticals and hospitals \\
5 & Construction & Steel, cement, paint, plastic, glass and \\
6 & Consumer & Food, beverages, packaging and other \\
7 & Automobile & Automobile accessories and allied firms \\
8 & Fuel \& Gas & Petroleum, oil, gas, diesel, and refinery \\
9 & Stationary & Paper, board, and printing \\
10 & Energy & Fibre cable, power generation, and power \\
11 & Chemicals & Chemicals and Fertilizers \\
12 & Technology & Technology and telecommunication \\
13 & Miscellaneou & Media, sports goods, footwear, jewelry, \\
\hline \hline
\end{tabular}

\subsection{Sentiment Proxies}

The investor sentiment is not straightforward to measure due to diversity in concepts about the sentiment and so about the measures. Reviewing the literature we find

${ }^{6}$ www.psx.com.pk. 
that there are various tools to measure the impact of sentiment. Researchers have used different instruments, which can be broad, classifying as the direct and indirect measures. Direct measures are those who can directly measure the investor mood and beliefs about the market, for example, investor surveys and mood proxies. Indirect proxies measure the behavior of economic agents with the analysis of fluctuations in the equity market. These proxies have following pros and cons.

a) Different researchers such as Brown and Cliff (2004) use Investor Survey. The survey is a direct response from individuals and it represents their attitude. Individuals tend to conceal their actual views so they respond differently to questions from their actual behaviour. Burghardt (2011) mentions sources of error in survey findings, which can be due to the interviewer, interviewee, and the questionnaire. Sometimes respondent cannot fully understand the question or cannot assess their own behaviour that is necessary for accurate answering. People do not have accurate and precise expectation about the future trend of the market. Hence, they are not able to give a precise and accurate answer.

Furthermore, response biases and measurement errors might cause a sentiment index to be biased, which is only partially related to real sentiment level (Zhang, 2008). Another mostly use direct sentiment proxy is mood proxy. Mood effect can be measured by seasonal, game results, and mega-events in an economy. Drakos (2010) uses terrorism activity as a good proxy to measure sentiment. However, it is hard to get such indicator at firm or industry level.

b) In behavioral finance literature, indirect proxies like liquidity (Baker \& Stein, 2004) and volatility premium (Baker, Wurgler, \& Yuan, 2012)) are considered a very good way to measure the prevalence of psychological impact in the stock market. Several market-level variables from firm level data and economic indicators are used to quantify stock market mania. Some of them are trades by retail investors, mutual fund flow, trading volume, dividend premium, discount on closed-end funds, option implied volatility, initial public offering (IPO) volume, return on the first day of IPO, equity issuance, and trade volume by insiders. 
The previous literature has provided evidence that the all of these proxies have a systematic investor sentiment component. Indirect proxies capture the investors' expectations about future price variations. These proxies have the ability to exhibit market reactions, which are due to high level of expressiveness in market data (Burghardt, 2011). The sentiment is considered as a tool, which generates mispricing. Following the previous literature, in this study, we use indirect proxies for investor sentiment measurement at industry level using firm-level data.

\subsection{Measurement of Sentiment}

Business cycle fluctuations have a tendency to affect sentiment proxies (McLean $\&$ Zhao, 2014). According to Finter and Ruenzi (2012), financial sentiment proxies already include a component related to the business cycle movements. To remove these macrorelated variations from our sentiment indicators, we orthogonalize our sentiment proxies on five macroeconomic variables. These macro series are growth in industrial production, the exchange rate, the inflation rate, the short-term interest rate, and the term premium. Regressing our sentiment proxies on these macro indicators eliminates the sentiment component that relates to business cycle fluctuations. Each industry's total sentiment index is calculated by the principal component approach.

After construction of industry wise indices, we construct a national index by using the sentiment values of these industries. Moreover, we explain the association between the return and sentiment at the current time and explore the pattern of return predictability with industrial and national sentiment indices.

\subsection{Construction of Sentiment Indices:}

We use three firm-level proxies, viz. volatility premium, turnover, and equity share to measure the investor sentiment.

\subsubsection{Volatility Premium}

Volatility in the stock returns exists due to the error of noise traders (Statman, 1995). Volatility premium is the relative value assessment of highly volatile stocks. It identifies the time when valuation on risky stocks is high or low relative to valuation on 
less risky stocks. It can also be interpreted as the measure of market-makers response to more volatile stocks.

Baker and Wurgler (2007) measure volatility by dividend premium and find that it can explain well the major historical trend in a firm's propensity to pay dividends. Another study by the same authors (Baker \& Wurgler, 2006) asserts that relative premium on dividend paying stock is inversely related to investor sentiment.

The motivation to use this variable is based on the theoretical prediction that sentiment has its strongest effect on volatile stocks. Volatility attracts day traders and proportion of individual ownership increases in volatility. Volatile stocks are subject to noise trader, arbitrage, and fundamental risk.

Volatility premium is defined as the natural log of the ratio of the value-weighted average market-to-book value of high volatile stocks to that of less volatile stocks. Volatility arises from daily trading activities. High volatility in stocks shows high dispersion in returns.

$$
\mathrm{PVol}_{i \mathrm{t}}=\ln \left[\frac{\text { Market }- \text { to }- \text { book }_{\mathrm{HVS}_{\mathrm{it}}}}{\text { Market }- \text { to }- \text { book }_{\mathrm{LVS}_{\mathrm{it}}}}\right]
$$

where ' $i$ ' indicates the number of firms and ' $\mathrm{t}$ ' represents years.

High Volatile Stocks (HVS) are stocks those have high volatility in return whereas, Less Volatile Stocks (LVS) are the stocks that have less standard deviation for the return series. Volatility premium can be analysed as the compensation of risky stocks. We follow the approach of Baker and Wurgler (2012) to calculate volatility premium. We sort stocks on the base of the standard deviation of the monthly return series in the previous year. We name stocks on the top as highly volatile stocks and lower stocks as the low volatile stocks.

We calculate book value of shares by using the formula:

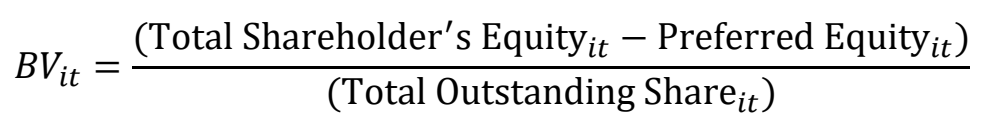

We calculate the market value of shares by multiplying the number of issued shares with the market price. Volatile stocks are those who are hard to value and more prone to sentimental shocks. 
Figure 3.1 portrays the pattern of volatility premium over time. Volatility premium remains positive in the period of our analysis but sometimes exhibits extreme values. Hence, we can infer that the market to book ratio of volatile stocks is more than the less volatile stocks. It implies that the volatile stocks have a comparatively higher market price.

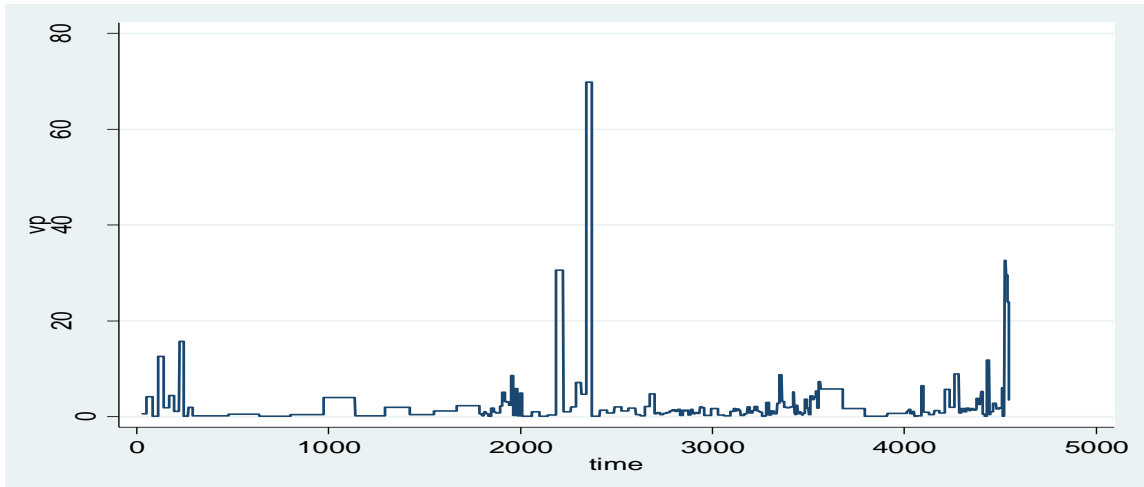

Figure 1: Volatility Premium for firms listed on PSX-100 index

\subsubsection{Market Turnover}

Our second sentiment proxy is turnover in the stock market. It is defined as the value of trade took place in a period. Specifically, it can be defined as the volume of trade for stocks in the stock exchange. High turnover shows the surge in trading volume, which is an indicator of the optimistic behaviour of investors. Ogunmuyiwa (2010) explains turnover as a measure of liquidity and relates it to investor sentiment.

Baker and Wurgler (2007) postulate that turnover exposes the difference of opinion among investors at the different time. High (low) turnover indicates the positivity (negativity) of investors' behaviour. Investor's pessimistic and optimistic behaviour affects the liquidity of stocks. In the literature, high market liquidity or trading volume has been considered to be a symptom of overvaluation of stocks (Baker \& Stein, 2004).

In a market with short-sale constraints, retail investors will only participate if they are optimistic. This increases trading volume so that liquidity should increase when traders are optimistic and increase demand for overvalued stocks. Only an optimistic investor invests in a market with short sale constraints (Finter et al., 2012). 
Turnover can be referred as a measure of irrational exuberance. Higher liquidity indicates overreaction of investors and as a result, overvaluation of stocks (Baker \& Wurgler, 2006). Baker and Wurgler (2012) use turnover as a sentiment proxy and quantify it by taking the natural log of the ratio of volume and capitalization.

$$
\text { TURN }_{i t}=\ln \left[\frac{\text { Volume }_{\text {it }}}{\text { Capitalization }_{\text {it }}}\right]
$$

where ' $\mathrm{i}$ ' is representing the number of firms and ' $\mathrm{t}$ ' is indicating years.

Volume is the number of shares traded in a security market during a specific period of time. It is simply the measure of activity or liquidity and calculates the number of shares traded. High trading volume is the indication of the overreaction of traders. Hong and Stein (2007) indicate high volume as a sign of the existence of biases and emotions that are playing a role in investors' decisions to trade. Price movement and volume cater the extent and direction of fluctuation in the stock market. Higher volume shows the high interest of market makers.

Market capitalization demonstrates the valuation of securities. Valuation in marketplace directly depends upon the level of psychological biases. If security is overvalued, then it shows the optimistic behaviour of investors and vice versa.

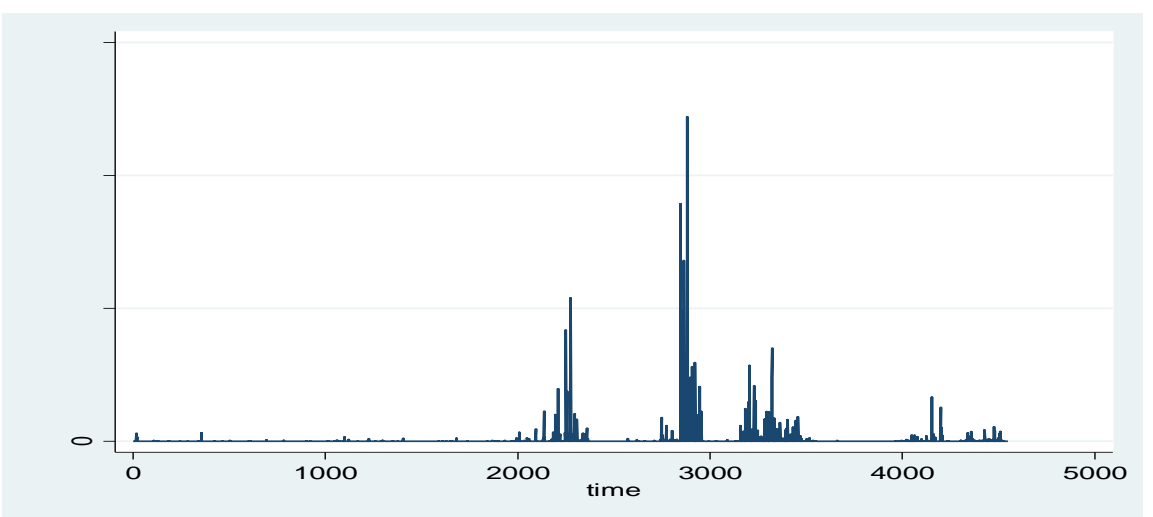

Figure 2: Graphical Presentation of Turnover in PSX-100 Index

Figure 2 plots turnover series over the period of 2000-2013. Graphical analysis exhibits a drift in the series. Before proceeding further, as is very common in the literature, 
we therefore stochastically de-trend this series by using the five-year moving average. We smooth series by subtracting the moving average of five years from the current value.

\subsubsection{Equity Share}

Equity share is the proportion of financing provided by the owners of a firm. This is a broader measure of equity financing that quantifies all equity instruments, not just IPOs. Equity share is defined as gross equity issuance divided by gross equity plus gross long-term debt issuance.

Overvalued firms are more likely to finance their new projects with equity financing. The trade-off theory of capital structure states that if a firm is using less equity and high leverage, then it is a sign of negative growth prospect. Equity share has a positive impact on investor sentiment. The magnitude of undervaluation or overvaluation indicates investor behaviour and overvaluation cause to increase equity share of the firm. Equity issuance decisions have an important impact on stock prices (Baker \& Wurgler, 2004).

Baker and Wurgler (2007) also describe equity share as a measure of total financing activity. A change in financing decisions reflects sentiment variation. Equity share is a market level factor due to its usage in investment decisions by institutional investors. It is a comprehensive measure of financing and also includes the impact of IPOs. In corporate finance literature, the market-timing theory of capital structure infers that firm managers will issue more equity when market participants are overvaluing equity shares in the stock market. We define equity share as:

$$
\mathrm{ES}_{\mathrm{it}}=\frac{\text { Gross Equity Share }_{\mathrm{it}}}{\text { Gross Equity Share }_{\mathrm{it}}+{\text { Long Term } \text { Debt }_{\text {it }}}}
$$

where ' $\mathrm{i}$ ' indicates the firms and ' $\mathrm{t}$ ' is at the time. Gross equity share is the total value of common shareholder's equity in the firm. Long-term debt indicates the debt obligations of a firm other than its current liabilities.

\subsection{Industrial Sentiment Indices}

We remove macro-level fluctuations from our sentiment proxies. For this purpose, we orthogonalize these proxies by using following equation. 


$$
\text { Sent_Proxies }{ }_{i t}=\alpha_{i}+\beta_{1} \mathrm{GIP}_{t}+\beta_{2} \mathrm{SIR}_{t}+\beta_{3} \mathrm{TP}_{t}+\beta_{4} \mathrm{ER}_{t}+\beta_{5} \mathrm{IR}_{\mathrm{t}}+\varepsilon_{i t}
$$

where, Sent_Proxies ${ }_{i}$ denotes the underlying sentiment variable i.e. volatility premium (VP), turnover (TOV), and equity share (ES). Explanatory variables GIP, SIR, TP, ER, and IR are growth in industrial production, the short-term interest rate, term premium, the exchange rate, and the inflation rate, respectively. Next, we obtain estimated residuals from this regression and then we use these residuals for further analysis. Specifically, we construct the industry-level investor sentiment index as follows.

$$
\text { Sent }_{i j t}^{\text {total }}=\beta_{1} P V O L_{i j t}+\beta_{2} \text { TURN }_{i j t}+\beta_{3} E S_{i j t}+\varepsilon_{i j t}
$$

where ' $\mathrm{i}$ ' is a number of firms in each industry, ' $\mathrm{j}$ ' ranges for 1 to 13 industries and ' $\mathrm{t}$ ' presents the time. We construct sentiment index for 13 industries by using the firm-level data of our sentiment proxies. Index coefficient $\left(\beta_{1}, \beta_{2}\right.$, and $\left.\beta_{3}\right)$ are estimated by using principal component approach. We use these annual industrial indices to form the composite national index as follows.

$$
\operatorname{Sent}_{t}^{\text {National }}=\beta_{1} \text { Sent }_{1 t}^{\text {total }}+\beta_{2} \operatorname{Sent}_{2 t}^{\text {total }}+\ldots+\beta_{13} \operatorname{Sent}_{13 t}^{\text {total }}+\varepsilon_{t}
$$

National industrial sentiment index is formed by the total industrial indices and ' $\mathrm{t}$ ' is presenting time variable. We determine the weight of each industry index based on the principal component analysis.

\subsection{Sentiment Effect on Contemporary and Future Stock Returns}

After construction of indices, we investigate whether investor sentiment affects stock returns. Specifically, we first investigate the impact of industrial sentiment index $\left(S E N T_{i j t}^{\text {total }}\right)$ on industrial stock returns $\left(R_{i j t}\right)$ for each industry included in our sample.

$$
R_{i j t}=c_{\circ}+\alpha S E N T_{i j t}^{\text {total }}+\varepsilon_{t}
$$

Next, we investigate the impact of fluctuations in national sentiment on market stock returns. $\alpha$ is the marginal effect of industrial sentiment on industrial stock returns. $\varepsilon_{t}$ is the error term.

$$
R_{t}=c_{\circ}+\omega S E N T_{t}^{\text {National }}+\varepsilon_{t}
$$


where $R_{t}$ is the market return i.e. monthly return of PSX-100 index, $\omega$ represents the marginal effect of national sentiment on monthly stock returns and $\varepsilon_{t}$ is the error term.

\section{EMPIRICAL RESULTS}

We present descriptive statistics of sentiment proxies and their correlation with the sentiment index in Table 2. All the proxies are significantly correlated, which shows that these indicators are measuring shared underlying dimensions. For all of these industries, first principal component attains the value greater than 1. Component loading is reported in the last column. Value of component loading can be used as the coefficient, same as the correlation or regression coefficient (Field, 2009). The overall magnitude of loadings are higher, however low values are also not problematic because of big sample size. Component loadings are weight between that particular variable and the component. Higher weight or correlation is a good sign for the principal component analysis. Higher load of variable shows higher relevancy in defining dimensionality. For all industrial sentiment indices, our selected proxies are significantly related to the respective index.

\begin{tabular}{|c|c|c|c|c|c|c|c|}
\hline & \multirow[b]{2}{*}{ Mean } & \multirow[b]{2}{*}{ SD } & \multirow[b]{2}{*}{ Min } & \multirow[b]{2}{*}{$\operatorname{Max}$} & \multicolumn{2}{|c|}{ Correlation with Sent ${ }_{i}$} & \multirow[t]{2}{*}{ Loadings } \\
\hline & & & & & Sent & PV & \\
\hline \multicolumn{8}{|l|}{ Sugar } \\
\hline $\mathrm{VP}$ & 0.04 & 1.69 & -2.57 & 2.75 & 0.70 & $(0.00)$ & 0.78 \\
\hline $\begin{array}{l}\text { TOV } \\
\text { TO } \\
\text { TOV }\end{array}$ & 6.99 & 1.78 & 0.00 & 11.33 & 0.60 & $(0.00)$ & 0.48 \\
\hline $\begin{array}{l}\text { ES } \\
\text { ES }\end{array}$ & 0.45 & 0.13 & 0.12 & 0.79 & 0.39 & $(0.00)$ & 0.39 \\
\hline \multicolumn{8}{|c|}{ Textile Composite } \\
\hline VP & -0.62 & 1.48 & -3.13 & 1.76 & 0.73 & $(0.00)$ & 0.63 \\
\hline TOV & 5.69 & 2.10 & 0.00 & 12.84 & 0.63 & $(0.00)$ & 0.72 \\
\hline ES & 0.42 & 0.14 & 0.00 & 0.85 & -0.33 & $(0.00)$ & -0.31 \\
\hline \multicolumn{8}{|c|}{ Engineering Equipment } \\
\hline VP & 0.42 & 1.01 & -3.06 & 0.77 & 0.11 & $(0.00)$ & 0.14 \\
\hline TOV & 6.72 & 1.89 & 2.22 & 12.48 & -0.63 & $(0.00)$ & 0.71 \\
\hline ES & 0.45 & 0.12 & 0.00 & 0.69 & 0.79 & $(0.00)$ & 0.69 \\
\hline \multicolumn{8}{|c|}{ Health Services } \\
\hline VP & -0.13 & 1.87 & -3.01 & 2.15 & 0.07 & $(0.00)$ & 0.18 \\
\hline TOV & 7.56 & 2.03 & 3.14 & 14.08 & -0.84 & $(0.00)$ & -0.74 \\
\hline ES & 0.53 & 0.10 & 0.24 & 0.79 & 0.56 & $(0.00)$ & 0.64 \\
\hline \multicolumn{8}{|c|}{ Construction Material } \\
\hline VP & 0.24 & 1.91 & -2.53 & 4.25 & 0.63 & $(0.00)$ & 0.68 \\
\hline
\end{tabular}




\begin{tabular}{|c|c|c|c|c|c|c|c|}
\hline TOV & 8.23 & 2.95 & 1.24 & 16.49 & 0.79 & $(0.00)$ & 0.73 \\
\hline ES & 0.44 & 0.13 & 0 & 0.80 & -0.11 & $(0.00)$ & -0.09 \\
\hline \multicolumn{8}{|c|}{ Consumable Products } \\
\hline VP & 0.19 & 1.22 & -2.16 & 2.19 & 0.24 & $(0.00)$ & 0.19 \\
\hline TOV & 5.61 & 1.99 & 0.00 & 11.86 & 0.70 & $(0.00)$ & 0.72 \\
\hline ES & 0.42 & 0.15 & 0.00 & 0.79 & 0.66 & $(0.00)$ & 0.67 \\
\hline \multicolumn{8}{|c|}{ Automobile and Allied } \\
\hline VP & -0.14 & 0.52 & -1.42 & 0.56 & 0.85 & $(0.00)$ & 0.69 \\
\hline TOV & 8.37 & 2.01 & 4.52 & 14.62 & 0.26 & $(0.00)$ & 0.31 \\
\hline ES & 0.48 & 0.10 & 0.17 & 0.64 & -0.48 & $(0.00)$ & -0.66 \\
\hline \multicolumn{8}{|c|}{ Fuel and Gas } \\
\hline VP & 0.13 & 0.48 & -0.97 & 0.73 & 0.81 & $(0.00)$ & 0.55 \\
\hline TOV & 10.15 & 4.31 & 2.30 & 17.92 & 0.28 & $(0.00)$ & 0.31 \\
\hline ES & 0.44 & 0.12 & 0.14 & 0.78 & 0.52 & $(0.00)$ & 0.77 \\
\hline \multicolumn{8}{|c|}{ Stationary } \\
\hline VP & 0.03 & 1.01 & -1.90 & 1.66 & -0.87 & $(0.00)$ & 0.71 \\
\hline TOV & 6.84 & 2.20 & 1.38 & 11.45 & 0.05 & $(0.00)$ & 0.11 \\
\hline ES & 0.48 & 0.13 & 0.21 & 0.84 & 0.49 & $(0.00)$ & 0.69 \\
\hline \multicolumn{8}{|c|}{ Energy } \\
\hline VP & -0.46 & 1.32 & -2.74 & 2.47 & -0.51 & $(0.00)$ & -0.65 \\
\hline TOV & 9.64 & 3.15 & 0.00 & 15.76 & 0.65 & $(0.00)$ & 0.52 \\
\hline ES & 0.43 & 0.11 & 0.14 & 0.66 & 0.52 & $(0.00)$ & 0.56 \\
\hline \multicolumn{8}{|c|}{ Chemicals and Fertilizers } \\
\hline VP & 0.57 & 0.73 & -1.01 & 2.17 & 0.48 & $(0.00)$ & 0.38 \\
\hline TOV & 8.87 & 3.38 & 0.00 & 15.99 & -0.66 & $(0.00)$ & -0.63 \\
\hline ES & 0.49 & 0.09 & 0.11 & 0.72 & 0.58 & $(0.00)$ & 0.67 \\
\hline \multicolumn{8}{|c|}{ Technology and Telecom } \\
\hline VP & -0.25 & 1.15 & -2.51 & 1.71 & 0.50 & $(0.00)$ & 0.46 \\
\hline TOV & 10.51 & 3.20 & 2.62 & 14.91 & 0.61 & $(0.00)$ & 0.52 \\
\hline ES & 0.45 & 0.13 & 0.12 & 0.65 & -0.65 & $(0.00)$ & -0.72 \\
\hline \multicolumn{8}{|c|}{ Miscellaneous } \\
\hline VP & 1.37 & 1.26 & -0.81 & 3.49 & -0.82 & $(0.00)$ & -0.78 \\
\hline TOV & 6.45 & 3.13 & 0.00 & 11.95 & 0.47 & $(0.00)$ & 0.49 \\
\hline ES & 0.51 & 0.13 & 0.15 & 0.78 & 0.29 & $(0.00)$ & 0.37 \\
\hline
\end{tabular}

\subsection{Impact of Industrial Sentiment on Industry-Specific Stock Returns}

The left side of Table 3 shows the effect of sentiment on contemporaneous returns. The sight side of the table provides the results of return predictability. Aforementioned regressions examine the relationship between industrial return and industrial sentiment, where, subscript ' $i$ ' represents the industries and ' $t$ ' is at the time. We can see from Table 3 that the sensitivity of stock returns to investor sentiment varies across industries. 


\begin{tabular}{|c|c|c|c|c|c|c|c|}
\hline \multirow[b]{2}{*}{ Industries } & \multirow[b]{2}{*}{ Return } & \multicolumn{3}{|c|}{$\underline{R}_{i, t}=\alpha_{i}+$ Sent $_{i, t}+\varepsilon_{i}$} & \multicolumn{3}{|c|}{$\underline{R}_{i, t+1}=\alpha_{i}+$ Sent $_{i, t}+\varepsilon_{i, t+1}$} \\
\hline & & Coefficient & S.E & PV & Coefficient & SE & PV \\
\hline \multirow{2}{*}{ Sugar } & Sent & $-0.34 * *$ & 0.14 & 0.02 & $-0.71 * * *$ & 0.15 & 0.00 \\
\hline & Intercept & $-0.53 * * *$ & 0.13 & 0.00 & -0.08 & 0.13 & 0.56 \\
\hline \multirow{2}{*}{ Textile Composite } & Sent & -0.17 & 0.12 & 0.15 & $-0.34 * * *$ & 0.12 & 0.00 \\
\hline & Intercept & $-0.45 * * *$ & 0.12 & 0.00 & 0.07 & 0.13 & 0.60 \\
\hline \multirow{2}{*}{ Engineering Equipment } & Sent & $-0.21 * * *$ & 0.11 & 0.00 & $-0.34 * * *$ & 0.11 & 0.00 \\
\hline & Intercept & $-0.47 * * *$ & 0.12 & 0.00 & 0.03 & 0.13 & 0.79 \\
\hline \multirow{2}{*}{ Health Service } & Sent & $-0.29 * *$ & 0.11 & 0.01 & $-0.26 * *$ & 0.12 & 0.03 \\
\hline & Intercept & $-0.52 * * *$ & 0.13 & 0.00 & -0.02 & 0.13 & 0.86 \\
\hline \multirow{2}{*}{ Construction Material } & Sent & -0.14 & 0.13 & 0.23 & $0.40 * * *$ & 0.14 & 0.00 \\
\hline & Intercept & $0.05 * * *$ & 0.01 & 0.00 & 0.96 & 1.34 & 0.48 \\
\hline \multirow{2}{*}{ Consumable Products } & Sent & -0.09 & 0.14 & 0.49 & $-0.42 * * *$ & 0.14 & 0.00 \\
\hline & Intercept & $-0.49 * * *$ & 0.13 & 0.00 & -0.09 & 1.31 & 0.99 \\
\hline \multirow{2}{*}{ Automobile and Allied } & Sent & $-0.19 * *$ & 0.08 & 0.02 & $-0.25 * * *$ & 0.08 & 0.00 \\
\hline & Intercept & $-0.51 * * *$ & 0.13 & 0.00 & -0.32 & 1.30 & 0.81 \\
\hline \multirow{2}{*}{ Fuel and Gas } & Sent & $-0.36 * * *$ & 0.10 & 0.00 & $-0.59 * * *$ & 0.11 & 0.00 \\
\hline & Intercept & $-0.57 * * *$ & 0.12 & 0.00 & -0.13 & 0.01 & 0.32 \\
\hline \multirow{2}{*}{ Stationary } & Sent & $0.31 * * *$ & 0.10 & 0.00 & $0.34 * * *$ & 0.11 & 0.00 \\
\hline & Intercept & $-0.52 * * *$ & 0.12 & 0.00 & -0.04 & 0.13 & 0.77 \\
\hline \multirow{2}{*}{ Energy } & Sent & $0.34 * *$ & 0.13 & 0.01 & 0.22 & 0.13 & 0.11 \\
\hline & Intercept & $-0.46^{* * *}$ & 0.12 & 0.00 & 0.17 & 1.32 & 0.81 \\
\hline \multirow{2}{*}{ Chemicals and Fertilizers } & Sent & $-0.42 * * *$ & 0.10 & 0.00 & $-0.47 * * *$ & 0.11 & 0.00 \\
\hline & Intercept & $-0.62 * * *$ & 0.12 & 0.00 & -0.14 & 0.13 & 0.21 \\
\hline \multirow{2}{*}{ Technology and Telecom } & Sent & -0.19 & 1.47 & 0.81 & -0.12 & 0.15 & 0.42 \\
\hline & Intercept & $-0.41 * * *$ & 0.13 & 0.00 & -0.01 & 0.13 & 0.10 \\
\hline \multirow{2}{*}{ Miscellaneous } & Sent & $0.43^{* * *}$ & 0.11 & 0.00 & $0.43 * * *$ & 0.11 & 0.00 \\
\hline & Intercept & $-0.97 * * *$ & 0.18 & 0.00 & $-0.48 * * *$ & 0.18 & 0.00 \\
\hline
\end{tabular}

Note: $* * * *, * *$, and $*$ show significance at the $1 \%, 5 \%$, and $10 \%$ level of significance, respectively.

The results of Table 3 indicate that sentiment is significantly influencing the current return level except for the textile, construction, consumption, and technology firms. The results suggest that stock returns in all of the industries are negatively affected by the industry-specific sentiment, except for the stationary, energy, and miscellaneous 
companies. The significant and negative impact of investor sentiment holds when we run the regression for one-period future returns.

Only for two out of thirteen industries (energy and technology), the influence of sentiment is statistically insignificant. Energy firms are having stocks, which are less likely to be inflated by sentimental shocks. Safe stocks have characteristics like bonds and they are stocks of big firms having a stable earning history. High speculative stocks are more sentiment sensitive and have an inverse association with the investor sentiment in the subsequent periods. Stocks of less stable industries are more prone to sentimental waves and biases.

We can relate our results to conventional finance theory. According to the market adjustment mechanism, if a shock or disturbance occurs in the market, which is shaking stock return, its effect must be reversed in the subsequent period and the market would be back at the equilibrium. Yet, by comparing the results of both regression models presented in Table 3, we came to know that stock market adjustment is not occurring.

Investor sentiment impact is in the same direction for current and future stock returns. It implies the existence of overreaction in industrial stock returns. If a stock market is efficient then the reverse effect should occur in both periods. In our analysis, this correction is only occurring for one industry i.e. construction materials. Yet, investor sentiment has an insignificant association with contemporary stock returns in this industry. All other industries are following the same trend for current and future stock returns. Therefore, we can infer that Pakistan equity market is not efficient enough to adjust the sentiment shocks and bring the market back to its initial level.

\subsection{Impact of Investor Sentiment in Equity Market}

We construct national sentiment index with the aim to explore the effect of sentiment in the overall equity market of Pakistan. Table 4 reports the correlation between the national sentiment and the variables, which are used to construct this index. The first column illustrates the score of components.

Sentiment indices of industries like sugar, textile, construction, consumable, automobile, fuel, and gas, technology, are forming one group on the positive side. 
However, sentiment index of industries like engineering, health, stationary, energy, miscellaneous is negatively correlated with national sentiment index. All industries' indices are significantly correlated with the national sentiment index. On average, the correlation among industrial indices is very high and significant which depicts the worth of including these variables in the construction of national sentiment index.

\begin{tabular}{|c|c|c|c|c|c|c|c|c|c|c|c|c|c|c|c|}
\hline & & \multicolumn{14}{|c|}{ Correlation among Industrial Indices } \\
\hline & : & 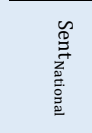 & 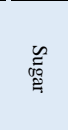 & $\begin{array}{l}\overrightarrow{0} \\
\stackrel{\mathbb{\pi}}{\hat{\sigma}}\end{array}$ & 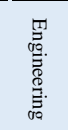 & 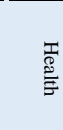 & 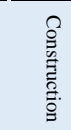 & 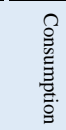 & 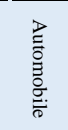 & 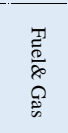 & 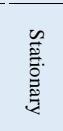 & 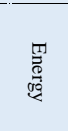 & 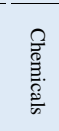 & 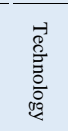 & $\frac{3}{v_{0}}$ \\
\hline Sugar & 0.29 & $0.72^{* * * *}$ & 1.00 & & & & & & & & & & & & \\
\hline Textile & 0.41 & $0.91 * * *$ & 0.74 & 1.00 & & & & & & & & & & & \\
\hline Engineering & -0.22 & $-0.55 * * *$ & 0.02 & -0.54 & 1.00 & & & & & & & & & & \\
\hline Health & -0.25 & $-0.62 * * *$ & -0.22 & -0.63 & 0.95 & 1.00 & & & & & & & & & \\
\hline Construction & 0.38 & $0.95^{* * *}$ & 0.86 & 0.96 & -0.48 & -0.65 & 1.00 & & & & & & & & \\
\hline Consumable products & 0.15 & $0.36^{* * * *}$ & 0.85 & 0.39 & 0.11 & -0.20 & 0.63 & 1.00 & & & & & & & \\
\hline Automobile & 0.37 & $0.92^{* * * *}$ & 0.54 & 0.91 & -0.42 & -0.39 & 0.76 & 0.05 & 1.00 & & & & & & \\
\hline Fuel \& Gas & 0.23 & $0.57^{* * *}$ & 0.93 & 0.58 & 0.34 & 0.13 & 0.66 & 0.73 & 0.49 & 1.00 & & & & & \\
\hline Stationary & -0.31 & $-0.76 * * * *$ & -0.36 & -0.74 & 0.24 & 0.14 & -0.53 & 0.17 & -0.95 & -0.42 & 1.00 & & & & \\
\hline Energy & -0.07 & $-0.16 * * *$ & 0.25 & -0.13 & -0.07 & -0.32 & 0.15 & 0.70 & -0.53 & 0.04 & 0.76 & 1.00 & & & \\
\hline Chemicals & -0.09 & $-0.23 * * *$ & 0.17 & -0.24 & 0.91 & 0.90 & -0.27 & 0.03 & -0.02 & 0.51 & -0.19 & -0.40 & 1.00 & & \\
\hline Technology & 0.38 & $0.92 * * *$ & 0.44 & 0.92 & -0.80 & -0.82 & 0.83 & 0.11 & 0.87 & 0.22 & -0.70 & -0.19 & -0.51 & 1.00 & \\
\hline Miscl. & -0.17 & $-0.42 * * *$ & -0.16 & -0.39 & -0.16 & -0.31 & -0.16 & 0.35 & -0.72 & -0.37 & 0.89 & 0.91 & -0.55 & -0.31 & 1.00 \\
\hline
\end{tabular}

After having constructed the national sentiment index, we explore the relationship between the national level sentiment and the stock return of PSX. Table 5 shows the relationship between investor sentiment and stock returns for the overall stock market of Pakistan. The first model, reported on the left side, analyses the impact of national sentiment index on current stock returns. The increase of one point in investor sentiment 
will decrease 34 basis point of monthly stock returns in the current period. This finding suggests that the impact of sentiment on the current returns is negative and statistically significant at the $1 \%$ level of significance.

We estimate the second model to explore the pattern of return predictability. The estimates of the second model show that for the next month, the investor sentiment has a significant forecasting power. Specifically, the estimated coefficient suggests that one-unit increase in the sentiment index will decrease stock returns in the next month by $14 \%$.

\begin{tabular}{|l|c|c|c|c|l|l|l|l|}
\hline Table 5: National Sentiment Index and Stock Returns \\
\hline & \multicolumn{5}{|c|}{ Return $_{\boldsymbol{t}}$} & \multicolumn{5}{c|}{ Return $_{\boldsymbol{t}+\boldsymbol{1}}$} \\
\hline & Coef. & S.E & t-stat & p-value & Coef. & S.E & t-stat & p-value \\
\hline Sent $_{t}$ & $-0.34 * * *$ & 0.07 & -4.31 & 0.00 & $-0.14 *$ & 0.09 & -1.69 & 0.09 \\
\hline Intercept & 0.01 & 1.96 & -0.01 & 0.99 & $0.44 * *$ & 0.21 & 2.12 & 0.03 \\
\hline
\end{tabular}

Note: $* * * *, * *$, and $*$ show significance at the $1 \%, 5 \%$, and $10 \%$ level of significance, respectively.

Behavioural shocks take some time to fully integrate into financial markets. This time-taking adjustment process is the reason for return predictability. Thus, these shocks predict future stock returns. Less liquid stock markets are more likely to be affected by sentiment e.g. Asian stock markets. Liquidity becomes a constraint for implementation of arbitrage strategies. Behavioural biases have higher tendency to defy stock prices in countries that have less market integrity and have a culture to follow the herd, such as Pakistan equity market.

\section{CONCLUSION}

Investor sentiment might be termed as a tendency to trade on noise rather than information. In this paper, we found that there is a significant relationship between investor sentiment and stock returns of firms traded on Pakistan Stock Exchange. We also found that sentiment effect remains influential for stock returns of upcoming period. Our results suggest that the nature of the relationship between investor sentiment and stock returns varies across industries. In our study, for most of the industry, investor sentiment index has a significant and negative impact on stock returns. We further found that the direction of 
the relationship between return and sentiment remains same for the current and future period. This indicates that investors overreact to the available information and mispricing exists for a prolonged time. The industry-wise analysis also suggests that the level and direction of sentiment effect varies substantially across the industries included in the sample.

We also quantified national sentiment index by using the industrial sentiment measures. Our findings related to national sentiment index indicate the negative relationship of sentiment with current stock returns. We also found that investor sentiment is a strong contrarian predictor of stock returns in Pakistan equity market.

Taken together, our results suggest that return predictability is possible by using investor sentiment information. Thus, we argued that market efficiency is a half-truth in Pakistan. Our results on the role of sentiment in determining current and future returns help investors to enhance the efficiency of investment and portfolio management. For future research, it would be worthwhile to measure sentiment separately for individual and institutional investors to see the differential impact on stock returns.

\section{REFERENCES}

Baker, M., \& Stein, J. C. (2004). Market liquidity as a sentiment indicator. Journal of Financial Markets, 7(3), 271-299.

Baker, M., \& Wurgler, J. (2006). Investor sentiment and the cross-section of stock returns. the Journal of Finance, 61(4), 1645-1680.

Baker, M., \& Wurgler, J. (2007). Investor sentiment in the stock market: National Bureau of Economic Research Cambridge, Mass., USA.

Baker, M., Wurgler, J., \& Yuan, Y. (2012). Global, local, and contagious investor sentiment. Journal of financial economics, 104(2), 272-287.

Berger, D., \& Turtle, H. (2012). Cross-sectional performance and investor sentiment in a multiple risk factor model. Journal of Banking \& Finance, 36(4), 1107-1121.

Bondt, W. F., \& Thaler, R. (1985). Does the stock market overreact? the Journal of Finance, 40(3), 793-805.

Brown, G. W., \& Cliff, M. T. (2004). Investor sentiment and the near-term stock market. Journal of Empirical Finance, 11(1), 1-27.

Burghardt, M. (2011). Retail Investor Sentiment and Behavior: An Empirical Analysis: Springer Science \& Business Media.

Chen, H., Chong, T. T. L., \& She, Y. (2014). A principal component approach to measuring investor sentiment in China. Quantitative Finance, 14(4), 573-579.

Chen, M.-P., Chen, P.-F., \& Lee, C.-C. (2013). Asymmetric effects of investor sentiment on industry stock returns Panel data evidence. Emerging Markets Review, 14(3), 35-54. 
Cohen, L., \& Frazzini, A. (2008). Economic links and predictable returns. the Journal of Finance, 63(4), 19772011.

Drakos, K. (2010). Terrorism activity, investor sentiment, and stock returns. Review of Financial Economics, 19(3), 128-135.

Fama, E. F. (1965). The behavior of stock-market prices. The Journal of Business, 38(1), 34-105.

Field, A. (2009). Discovering statistics using SPSS: Sage publications.

Finter, P., \& Ruenzi, S. (2012). The impact of investor sentiment on the German stock market. Zeitschrift für Betriebswirtschaft, 82(2), 133-163.

Glushkov, D. (2006). Sentiment beta. The University of Texas at Austin. Working paper.

Glushkov, D., \& Bardos, K. S. (2012). Importance of Catering Incentives for Growth Dynamics. Journal of Behavioral Finance, 13(4), 259-280.

Gupta, R., \& Basu, P. K. (2011). Weak form efficiency in Indian stock markets. International Business \& Economics Research Journal (IBER), 6(3), 57-64.

Lutz. (2010). The predictive power of stock market sentiment. Journal of the Econometric Society, 61(4), 821 856.

Lutz, C. (2015). The Asymmetric Effects of Investor Sentiment. Macroeconomic Dynamics, 1-27.

McLean, R. D., \& Zhao, M. (2014). The business cycle, investor sentiment, and costly external finance. The Journal of Finance, 69(3), 1377-1409.

Sapra, S. G., \& Zak, P. J. (2010). Eight lessons from neuroeconomics for money managers. Available at https://www.cfapubs.org/doi/abs/10.2470/rf.v2010.n2.6.

Schmeling, M. (2009). Investor sentiment and stock return: some international evidence. Journal of Empirical Finance, 16(3), 394-408.

Shefrin, H. (2014). Investors' Judgments, Asset Pricing Factors, and Sentiment. Asset Pricing Factors, and Sentiment. Europen Financial Magement, 21(2), 205-227.

Shiller, R. J. (1987). Investor behavior in the October 1987 stock market crash: Survey evidence: National Bureau of Economic Research Cambridge, Mass., USA.

Shleifer, A. (2000). Inefficient markets: An introduction to behavioral finance: Oxford university press.

Statman, M. (1995). Behavioral finance versus standard finance. AIMR Coference Proceeding, 7, 14-22.

Statman, M. (2010). What is behavioral finance? Business Education \& Technology Journal, 2(2), 1-9.

Statman, M. (2014). Behavioral finance: Finance with normal people. Borsa Istanbul Review, 14(2), 65-73.

Thaler, R. H. (1999). The end of behavioral finance. Financial Analysts Journal, 55(6), 12-17.

Wu, P.-C., Liu, S.-Y., \& Chen, C.-Y. (2016). Re-examining risk premiums in the Fama-French model: The role of investor sentiment. The North American Journal of Economics and Finance, 36(4), 154-171.

Zhang, C. (2008). Defining, modeling, and measuring investor sentiment. Working paper, Department of Economics, University of California, Berkeley. 